\title{
Optimization Model on the Effect of Clove Oil, Formaldehyde, and Chitosan Added to Batik Fabric Colored with Gambier (Uncaria gambir Roxb): Antifungal Properties and Stability
}

\author{
Edia Rahayuningsih ${ }^{1, *}$, Felix Arie Setiawan ${ }^{2}$, Conny Julanda Ayanie ${ }^{1}$, Ambrosius Aditya Antoko $^{1}$, \\ Yosephine Intan Ayuningtyas ${ }^{1}$, and Himawan Bayu Petrus ${ }^{1}$ \\ ${ }^{1}$ Department of Chemical Engineering, Universitas Gadjah Mada, Jl. Grafika No 2, Yogyakarta 55281, Indonesia \\ ${ }^{2}$ Department of Chemical Engineering, Universitas Jember, \\ Jl. Kalimantan No. 37, Kampus Tegalboto, Jember, Jawa Timur 68121, Indonesia
}

* Corresponding author:

email:edia_rahayu@ugm.ac.id

Received: May 21, 2019

Accepted: June 20, 2019

DOI: $10.22146 /$ ijc. 46038

\begin{abstract}
Triggered by the concept of sustainability, the use of natural dyes in batik fabric processing has increased recently. To inhibit fungus growth on batik fabric colored with natural dyes, either clove oil or formaldehyde was added as an antifungal agent. To increase the stability of the interaction between the antifungal agent and the batik fabric, chitosan was used as a crosslinker. A modified version of the standard tests American Association of Textile Chemists and Colorists (AATCC) 30 and Response Surface Methodology (RSM) was applied as the characterization method. The results showed that the growth percentage of fungi in Batik treated with either clove oil or formaldehyde was much lower than that in the control sample. Growth of Aspergillus niger could be prevented by about 32\% using clove oil and 94\% using formaldehyde. The optimal condition was obtained with $1 \%$ chitosan as a crosslinking reagent, 15.91 ppm of formaldehyde, and 60-min immersion time, with absorbance intensity of formaldehyde crosslinking solution and fungus growth areas being 0.159 and $2.47 \%$, respectively.
\end{abstract}

Keywords: Gambier natural dye; crosslinking; antifungal; chitosan; clove oil; formaldehyde

\section{- INTRODUCTION}

Known for its diverse cultures and art, Indonesia originated the use of Batik as a cultural art medium. Since October $2^{\text {nd }}, 2009$, batik has been designated as an element of non-material global cultural heritage [1]. Batik is a patterned fabric made using a wax-resistant dyeing technique. The patterned designs display an important and intimate philosophy regarding social life. Aside from batik motifs, designs, and philosophies, the charm of the beauty of batik is also enhanced by the coloring used.

Both natural and synthetic dyes have been used in the coloring process of batik fabric. Before the mid- $19^{\text {th }}$ century, batik coloring was done using natural dyes derived from plant extracts such as stems, bark, leaves, seeds, flowers, and other parts of plants. After the discovery of synthetic dyes, the use of natural dyes in the coloring process of batik fabric was abandoned because synthetic dyes were affordable and easy to use [2]. In the early $20^{\text {th }}$ century, the development of natural dyes for textiles re-emerged. Meanwhile, public awareness of the health and environmental impacts of synthetic dyes led to increasingly strict regulations implemented by governments [3-4]. The use of synthetic textile dyes which contain heavy metals can have environmental impacts such as water, soil, and air pollution [5]. In addition, the content of heavy metals in synthetic dyes can have a direct effect on humans, such as skin cancer and other types of cancers, brain damage, cerebrovascular disease, and lung disease, so that the use of natural dyes becomes an option to overcome these problems.

Natural dyes can be obtained from various sources such as insects, minerals, fungi, and different parts of plants such as leaves, roots, flowers, fruit, and skin [6]. 
As natural derivative products, natural dyes have several advantages such as being environmentally friendly, nontoxic, have unique color, and high degradability [7-8]. These advantageous properties are also supported with antimicrobial properties contained in several natural dyes. Antimicrobial activity is an important property to make long-lasting and favorable batik fabric especially in tropical countries with high humidity.

Gambier extract as a natural dye derived from the Gambier plant (Uncaria gambir Roxb) contains antimicrobial activity [9]. The chemical constituent on Gambier which is responsible for the antimicrobial activity is tannins. Gambier extract consists of $24.56 \%$ tannins, which produces brownish color [10]. The humid environment during storage and usage of fabric enhances the growth of microorganisms such as bacteria and fungi [11]. Fungi and mold worsen the fabric quality by ripping and damaging the fabric fiber; meanwhile, bacteria are responsible for unpleasant odor [12]. Antimicrobial agents can be classified into compounds that are biocidal (killing microorganisms) and biostatic (inhibiting adhesion and growth) $[11,13]$. For customer comfort and satisfaction, the addition of antifungal agents has been conducted for several natural dyes coloring processes to inhibit fungi growth on the fabric. Several antifungal agents are sufficient to inhibit or kill microorganism such as clove oil and formaldehyde [14-16]. Clove oil has antifungal properties against yeast, filamentous fungi, and pathogenic fungi in humans [15,17]. Phenolic compounds as clove oil constituents have antimicrobial and phytotoxic properties, and can kill insects [16]. Another study also reported that clove oil has antifungal properties against mold, yeast, and fungi on the human pathogen [17]. On the other hand, formaldehyde has disinfectant properties that can inhibit microbial activity such as bactericide, tuberculocide, fungicide, virucide, and sporicide [10,14,18-21].

The crosslinking between cellulose and the antifungal compound is one of the critical stabilization processes in the textile industry. A suitable crosslinking method can prevent the release of the antifungal compound from the cellulose fiber. In this study, either clove oil or formaldehyde was immobilized on the
Gambier-colored batik fabric, using chitosan as the crosslinker. The possible reaction of crosslinking between chitosan to cellulose using formaldehyde and clove oil have not been proposed yet. The optimum condition was examined using Response Surface Methodology (RSM) as a fastness test, Analysis of Variance (ANOVA) as a significance test, and Least Significant Difference (LSD) for fungal growth. Furthermore, Aspergillus niger, a well-known and fast growing fungus, was used to study the antifungal activity. As mentioned above, the application of antimicrobials, especially antifungals, to fabrics would increase the quality of the fabric. The study should serve as a reference for the beneficial use of Gambier natural dyes and other natural dyes to gain stable and longlasting batik products.

\section{- EXPERIMENTAL SECTION}

\section{Materials}

The materials used in this study are presented in Table 1. In this research, commercially-available Gambier powder derived from natural Gambier leaves as illustrated in Fig. 1 was used to maintain the same quality of coloring agent material during the entire study.

\section{Procedure}

\section{Material preparation}

Gambier powder was diluted in a stirring flask using distilled water with feed-solvent ratio $(\mathrm{w} / \mathrm{v})$ $0.048 \mathrm{~g} / \mathrm{L}$ for $2 \mathrm{~h}$ at $100^{\circ} \mathrm{C}$. The solution was cooled and stabilized for one day to precipitate insoluble solid. After filtration, the filtrate became the coloring agent. Cotton fabric was uniformly cut into a rectangular size $5 \mathrm{~cm} \times$ $5 \mathrm{~cm}$. The coloring process was carried out by soaking the fabric samples on the coloring solution as illustrated in Fig. 2 for $30 \mathrm{~min}$ at $95^{\circ} \mathrm{C}$ continued by the drying process. The dry fabric was soaked in $20 \mathrm{~g} / \mathrm{L}$ alum solution for $30 \mathrm{~min}$ followed with prolonged drying. The fabric was washed with hot water and rinsed with cold water continued by the drying process. Chitosan $0.1 \%$ $(\mathrm{w} / \mathrm{v})$ was dissolved in $1 \%$ acetic acid solution. Either clove oil-Tween 80 or formaldehyde was added into a chitosan solution with a predetermined concentration to 
Table 1. List of materials

\begin{tabular}{lllc}
\hline Material & Source & Brand & Purity \\
\hline Gambier powder & Local Market - Yogyakarta & Bulk & - \\
Cotton fabric & Workshop Batik Indigo - Yogyakarta & Bulk & - \\
Chitosan & Chem-mix Pratama - Yogyakarta & Bulk & - \\
Clove oil & Local Market - Yogyakarta & Lansida & $100 \%$ \\
Formaldehyde & Workshop Batik Indigo - Yogyakarta & Bulk & $35 \%$ \\
Sodium sulfate & Chemical Engineering Laboratory - UGM & Merck & $99.99 \%$ \\
Acetylacetone & Local Market - Yogyakarta & Merck & $99.5 \%$ \\
Acetic acid & Chemical Engineering Laboratory - UGM & Merck & $96 \%$ \\
Ammonium sulfate & Chemical Engineering Laboratory - UGM & Merck & $99.9 \%$ \\
Alum & Workshop Batik Indigo - Yogyakarta & Bulk & - \\
Tween 80 n-nonionic & Local Market - Yogyakarta & Sigma-Aldrich & - \\
Distilled water & Chemical Engineering Laboratory - UGM & Bulk & - \\
Aspergillus niger & Microbiology Laboratory - UGM & - & - \\
Potato Dextrose Broth & Microbiology Laboratory - UGM & Sigma-Aldrich & - \\
\hline
\end{tabular}
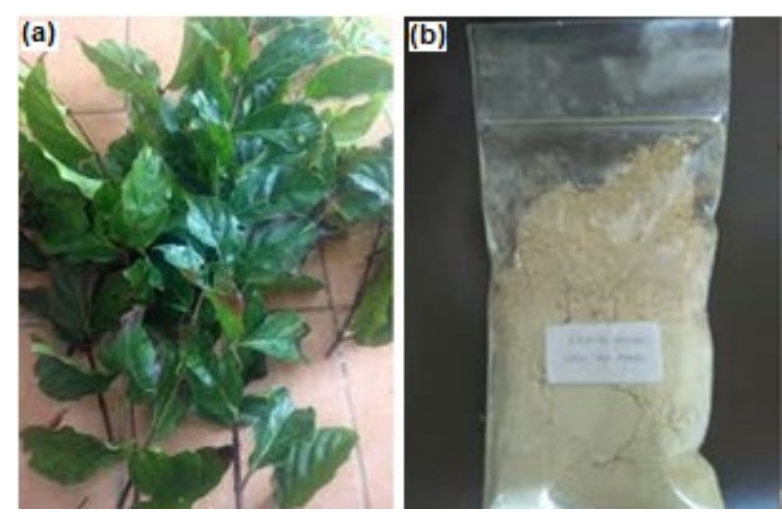

Fig 1. Gambier as (a) raw leaves and (b) powder extract

produce the antifungal compound solution. Tween 80 was used as an emulsifier for clove oil to be attached into chitosan.

\section{Antifungal application}

The fabric was dipped in each antifungal solution. The fabric was then dried at room temperature. The dipping process duration was varied by 10,25 , and $60 \mathrm{~min}$.

Measurement of absorbance on crosslinking strength using fastness test. To examine crosslinking strength, each clove oil-treated fabric was dissolved with a $0.3 \%(\mathrm{w} / \mathrm{v})$ Tween 80 solution at $30{ }^{\circ} \mathrm{C}$ and left overnight. Then, $5 \mathrm{~mL}$ samples were taken and analyzed using UV-VIS Spectrophotometer. The absorbance of each sample was measured by UV-VIS Spectrophotometer

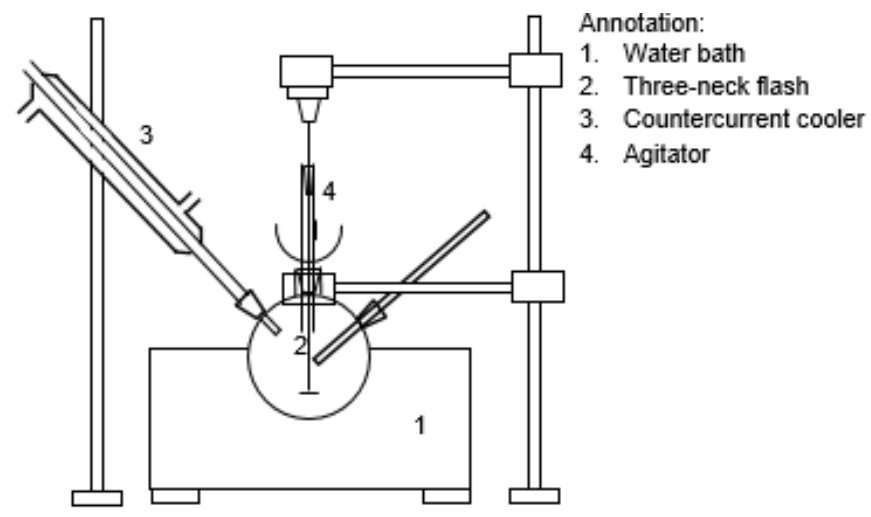

Fig 2. Batch coloring process

at $396.4 \mathrm{~nm}$ wavelength [22]. Meanwhile, absorbance test method on formaldehyde was conducted using EN ISO 14184-1 standard method. Each sample treated with formaldehyde as the antifungal agent was contacted with distilled water at $40{ }^{\circ} \mathrm{C}$ for $1 \mathrm{~h}$. Set of apparatus was applied to maintain temperature. The liquid phase was filtered and reacted with acetylacetone, namely Nash reactive, to produce a yellow solution. The absorbance of each formaldehyde-treated sample was measured with UV-VIS Spectrophotometer at $412.9 \mathrm{~nm}$ wavelength.

\section{Antifungal analysis}

The Modified American Association of Textile Chemists and Colorists (AATCC) Test Method 30 was used to observe the antifungal activity. The positive control that has been colored with Gambier natural dyes 
Table 2. Experimental design and level of independent variables

\begin{tabular}{lccc}
\hline \multirow{2}{*}{ Independent Variable } & \multicolumn{3}{c}{ Range of level } \\
\cline { 2 - 4 } & -1 & 0 & 1 \\
\hline${ }^{1,2}$ Chitosan concentration (CA), \% & 0.1 & 0.225 & 1 \\
${ }^{1}$ Clove oil concentration (CB), \% & 0.5 & 1.5 & 2.5 \\
${ }^{2}$ Formaldehyde concentration (CF), ppm & 10 & 22.5 & 50 \\
${ }^{1,2}$ Time (T), min & 10 & 25 & 60 \\
${ }^{1}$ optimization variable for clove oil crosslinking & & & \\
${ }^{2}$ optimization variable for formaldehyde crosslinking & &
\end{tabular}

was also performed in this study. Each treated sample was cut in a circular shape with a $6 \mathrm{~cm}$ diameter about the size of a petri dish. Aspergillus niger cultured in Potato Dextrose Broth (PDB) growth medium was used in the antifungal test. $\mathrm{PDB}$ was used to evaluate the spore germination and the growth of Aspergillus niger [23]. PDB medium $0.75 \mu \mathrm{L}$ and Aspergillus niger suspension were dropped-coated on the fabrics using an inoculation needle. Furthermore, fungal growth was observed for $72 \mathrm{~h}$.

\section{Data analysis}

In accordance to the modified AATCC 30, the fungal growth analysis was conducted visually with the colony diameter measurement. The diameter size of each replication had been carried out by measuring the average diameter of six samples of fungal growth. Calculation of sample area percentage was then evaluated using the following equation:

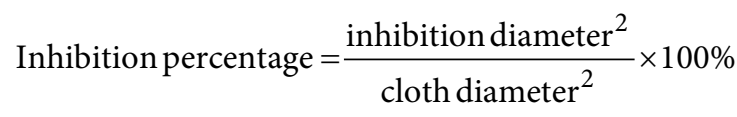

The optimization was determined by three-level factorial design using Response Surface Methodology (RSM) in the Minitab ${ }^{\circ}$ program on the absorbance data. The dependent variable in this study was the absorbance measured by UV-Vis Spectrophotometer. Meanwhile, the individual independent variables could be seen in Table 2 for every antifungal agent. The optimum chitosan and clove oil concentration to inhibit the microbial growth are $0.225 \%$ and $1.5 \%$ respectively [22,24]. Moreover, the limit of formaldehyde concentration is below $75 \mathrm{ppm}$ for fabrics used in clothing [25].

The non-linear polynomial equation is generally used to correlate the variables, with the responses as dependent variables and the factor as an independent variable. The basic equation for the second-order response surface model followed [26-28]:

$\mathrm{Y}=\beta_{0}+\sum_{\mathrm{i}-1}^{\mathrm{k}} \beta_{\mathrm{i}} \mathrm{x}_{\mathrm{i}}+\sum_{\mathrm{i}-1}^{\mathrm{k}} \beta_{\mathrm{ii}} \mathrm{x}_{\mathrm{ii}}^{2}+\sum_{1<\mathrm{i} \leq \mathrm{j}}^{\mathrm{k}} \beta_{\mathrm{ij}} \mathrm{x}_{\mathrm{i}} \mathrm{x}_{\mathrm{j}}+\varepsilon$

where, Y: response; $\beta_{0}$ : constant coefficient; $\beta_{\mathrm{i}}, \beta_{\mathrm{ii}}$ and $\beta_{\mathrm{ij}}$ : the coefficients for the linear, quadratic and interaction effect respectively; $x_{i}$ and $x_{j}$ : factors ( $i$ and $j$ are the range from 1 to $\mathrm{k}$ ); and $\varepsilon$ : error.

A coefficient of determination $\left(\mathrm{R}^{2}\right)$ was observed during the optimization process [29]. Mushroom growth can also be classified with several scales [16], namely: 0: No fungal growth is seen using microscopic observation, 1: Fungal growth is seen using microscopic observation, however, is not seen using bare eyes, 2: Fungal growth covers $25 \%$ of the test area, 3: Fungal growth covers $50 \%$ of the test area, 4: Fungal growth covers $75 \%$ of the test area, 5: Fungal growth covers $100 \%$ of the test area.

\section{- RESULTS AND DISCUSSION}

In this study, the quality of the antifungal agent was evaluated using two analytical methods. The first method analyzed the ability of the substance to attach on the fabric using fastness tests. The second method analyzed the capability of the antifungal agent using antifungal analysis. To enhance the interaction strength between the antifungal compound and the cellulose fiber, both on the first method and second method, chitosan was used as the crosslinker. These two methods were very useful to describe the quality of antifungal agents on the application process. The proposed reaction mechanism of cellulose and clove-oil or formaldehyde using chitosan as crosslinker can be seen in Fig. 3(a) and (b) respectively. 


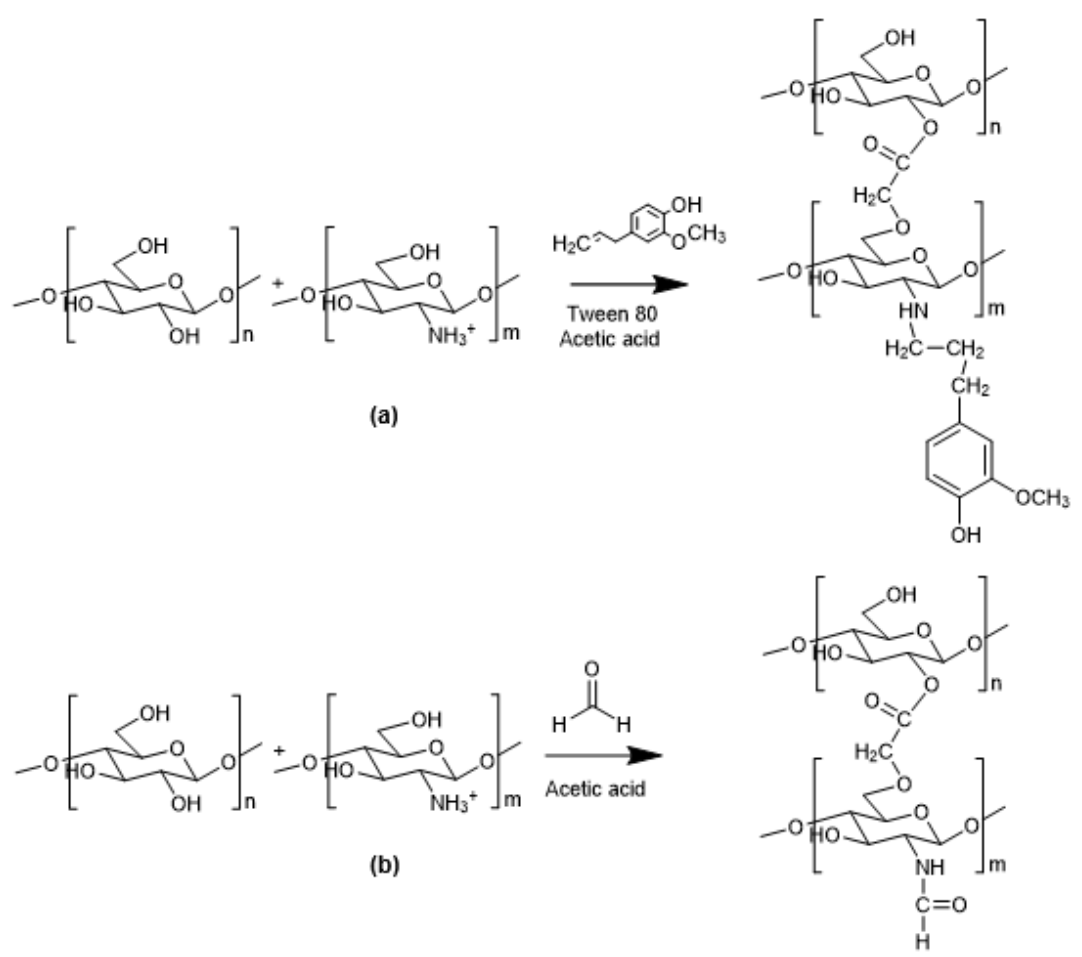

Fig 3. Proposed crosslinking reaction in the study (a) cellulose-chitosan-clove oil and (b) cellulose-chitosanformaldehyde
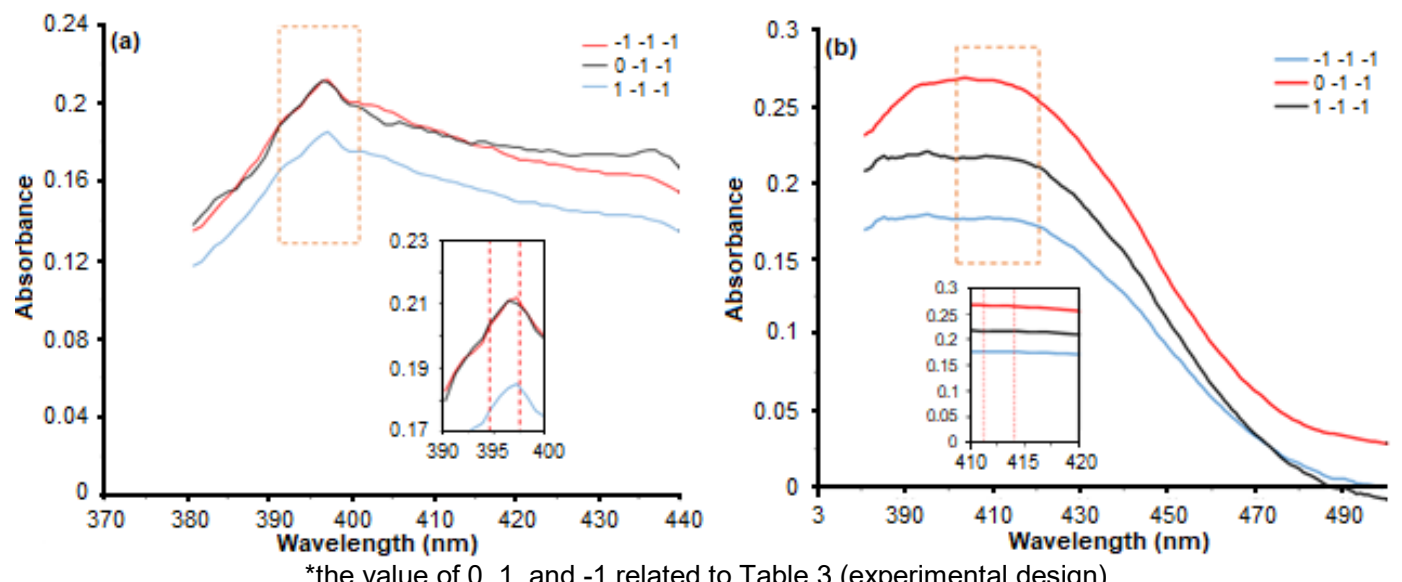

Fig 4. UV-Vis Spectrophotometry results of (a) clove oil crosslinking sample and (b) formaldehyde crosslinking sample

\section{Identification of Clove Oil and Formaldehyde Using UV-Vis Analysis}

Fastness tests were conducted using UV-Vis spectrophotometer on clove oil and formaldehyde crosslinking with chitosan. The selected spectrophotometry results are presented in Fig. 4(a) and (b). The figures also present the similarity trend of chitosan concentration variation when other variables were defined at the lowest value. Fig. 4(a) shows optimum absorption $\left(\lambda_{\max }\right)$ around wavelength $394.4-397.5 \mathrm{~nm}$ that fits the wavelength of clove oil-chitosan crosslinking solution. Meanwhile, the same tendency occurred in the formaldehyde-chitosan crosslinking solution measurement with maximum absorption around wavelength 411.3-414.1 nm shown in Fig. 4(b). Thus, the selected wavelength for each analysis could be used to evaluate the optimum condition of crosslinking strength using the fastness test. 


\section{Determination of Crosslinking Strength Using Fastness Test}

The absorbance of the samples was used to determine the amount of antifungal agent released from the cotton fabric into a liquid phase. Absorbance resulted from UV-Vis Spectrophotometry generally represents the concentration of a substance in a specific wavelength. Thus, the correlation between absorbance and targeted substance concentration was assumed to be linear. Model fitting was also performed to obtain the predicted value of each absorbance using Minitab ${ }^{\oplus}$. The predicted absorbance as responses of optimization could be seen in Table 3 with the empirical equation described below.

Optimum condition from the data on the presence of clove oil ${ }^{\mathrm{a}}$ and formaldehyde ${ }^{\mathrm{b}}$ with a crosslinking method; with i: input, $\mathrm{R}$ : input response, and $\mathrm{O}=$ output.

$$
\begin{aligned}
\mathrm{YB}= & 0.2456+0.109 \mathrm{CA}-0.0480 \mathrm{CB}-0.00087 \mathrm{~T}-0.158 \mathrm{CA}^{2} \\
& +0.0153 \mathrm{CB}^{2}+0.000013 \mathrm{~T}^{2}-0.0084 \mathrm{CA} \times \mathrm{CB}-0.000795 \mathrm{CA} \\
& \times \mathrm{T}+0.000098 \mathrm{CB} \times \mathrm{T} \\
\mathrm{YF}= & 0.1739+0.444 \mathrm{CA}-0.00151 \mathrm{CF}-0.00185 \mathrm{~T}-0.338 \mathrm{CA}^{2} \\
& +0.000025 \mathrm{CF}^{2}+0.000032 \mathrm{~T}^{2}+0.001559 \mathrm{CA} \times \mathrm{CF} \\
& -0.001984 \mathrm{CA} \times \mathrm{T}-0.000014 \mathrm{CF} \times \mathrm{T}
\end{aligned}
$$

where $\mathrm{CA}$ is chitosan concentration, $\mathrm{CB}$ is clove oil concentration, $\mathrm{CF}$ is formaldehyde concentration, $\mathrm{T}$ is immersion time, YB is clove oil absorbance, and YF is

\begin{tabular}{|c|c|c|c|c|c|c|c|c|}
\hline \multirow{2}{*}{$\begin{array}{l}\text { Run } \\
\text { code }\end{array}$} & \multirow{2}{*}{${ }^{\mathrm{i}} \mathrm{CA}, \%$} & \multirow{2}{*}{${ }^{\mathrm{i}} \mathrm{T}, \mathrm{min}$} & \multicolumn{3}{|c|}{ Clove oil } & \multicolumn{3}{|c|}{ Formaldehyde } \\
\hline & & & ${ }^{\mathrm{i}} \mathrm{CB}, \%$ & ${ }^{\mathrm{R}} \mathrm{YB}$ data* & ${ }^{\circ}$ YB model & ${ }^{\mathrm{i}} \mathrm{CF}, \mathrm{ppm}$ & ${ }^{\mathrm{R}} \mathrm{YF}$ data* & ${ }^{\text {OYF model }}$ \\
\hline 1 & 0.100 & 10 & 0.5 & 0.211 & 0.227 & 5.00 & 0.172 & 0.191 \\
\hline 2 & 0.100 & 25 & 0.5 & 0.227 & 0.220 & 5.00 & 0.188 & 0.176 \\
\hline 3 & 0.100 & 60 & 0.5 & 0.228 & 0.228 & 5.00 & 0.195 & 0.198 \\
\hline 4 & 0.100 & 10 & 1.5 & 0.225 & 0.209 & 22.5 & 0.178 & 0.177 \\
\hline 5 & 0.100 & 25 & 1.5 & 0.259 & 0.204 & 22.5 & 0.185 & 0.158 \\
\hline 6 & 0.100 & 60 & 1.5 & 0.218 & 0.216 & 22.5 & 0.205 & 0.171 \\
\hline 7 & 0.100 & 10 & 2.5 & 0.226 & 0.223 & 50.0 & $0.143^{b}$ & 0.186 \\
\hline 8 & 0.100 & 25 & 2.5 & 0.195 & 0.219 & 50.0 & 0.151 & 0.161 \\
\hline 9 & 0.100 & 60 & 2.5 & 0.192 & 0.234 & 50.0 & 0.161 & 0.161 \\
\hline 10 & 0.225 & 10 & 0.5 & 0.212 & 0.232 & 5.00 & 0.264 & 0.231 \\
\hline 11 & 0.225 & 25 & 0.5 & 0.208 & 0.224 & 5.00 & 0.237 & 0.212 \\
\hline 12 & 0.225 & 60 & 0.5 & 0.216 & 0.229 & 5.00 & 0.200 & 0.225 \\
\hline 13 & 0.225 & 10 & 1.5 & 0.240 & 0.214 & 22.5 & 0.178 & 0.220 \\
\hline 14 & 0.225 & 25 & 1.5 & 0.217 & 0.207 & 22.5 & 0.164 & 0.198 \\
\hline 15 & 0.225 & 60 & 1.5 & 0.217 & 0.216 & 22.5 & 0.171 & 0.202 \\
\hline 16 & 0.225 & 10 & 2.5 & 0.225 & 0.226 & 50.0 & 0.266 & 0.235 \\
\hline 17 & 0.225 & 25 & 2.5 & 0.173 & 0.221 & 50.0 & 0.251 & 0.207 \\
\hline 18 & 0.225 & 60 & 2.5 & 0.295 & 0.233 & 50.0 & 0.197 & 0.197 \\
\hline 19 & 1.000 & 10 & 0.5 & 0.184 & 0.157 & 5.00 & 0.215 & 0.244 \\
\hline 20 & 1.000 & 25 & 0.5 & 0.145 & 0.140 & 5.00 & 0.200 & 0.203 \\
\hline 21 & 1.000 & 60 & 0.5 & 0.150 & 0.123 & 5.00 & 0.171 & 0.162 \\
\hline 22 & 1.000 & 10 & 1.5 & 0.077 & 0.132 & 22.5 & 0.305 & 0.255 \\
\hline 23 & 1.000 & 25 & 1.5 & 0.107 & 0.117 & 22.5 & 0.183 & 0.210 \\
\hline 24 & 1.000 & 60 & 1.5 & $0.059^{\mathrm{a}}$ & 0.103 & 22.5 & 0.182 & 0.160 \\
\hline 25 & 1.000 & 10 & 2.5 & 0.159 & 0.138 & 50.0 & 0.320 & 0.303 \\
\hline 26 & 1.000 & 25 & 2.5 & 0.146 & 0.124 & 50.0 & 0.217 & 0.251 \\
\hline 27 & 1.000 & 60 & 2.5 & 0.121 & 0.114 & 50.0 & 0.183 & 0.188 \\
\hline
\end{tabular}
formaldehyde absorbance. The most stable interaction between the antifungal compound and the fabric is demonstrated by the lowest absorbance data which was represented at run code 24 for clove oil addition and run

Table 3. Absorbance result as a parameter to quantify the degree of fastness 
code 7 for formaldehyde addition. Linear plotting of absorbance data with absorbance responses could be seen in Fig. 5. To give a clear explanation of each parameter effect in every treatment, the correlation of each parameter on absorbance was conducted as seen in Fig. 6.

Both Fig. 6(a) and (b) show that chitosan concentration (CA) gives the most significant effect on the absorbance changes. This can be seen from the range of mean values between the significant upper and lower levels. This observed phenomenon indicates that crosslinking strength significantly increases with a significant increase in chitosan concentration during material preparation and antifungal application. However, the higher chitosan concentration in formaldehyde increased the absorbance after fastness test, which was not preferable. We believe that the crosslinking process had not yet been established, leading to a higher release of the compounds from the fabric into the solution, and thus higher observed absorbance in the solution after the fastness test. Furthermore, both clove oil and formaldehyde show similar trend on the absorbance. While time (T) only had a significant effect on the formaldehyde addition, time duration reflected the immersion time of the cotton fabrics in the crosslinking solution (Fig. 6(b)). The results showed that clove oil crosslinking solution does not need extended time to infiltrate cotton fabric while formaldehyde crosslinking solution does require a longer time to stabilize on the cotton fabric surfaces.

Afterwards, the best condition for the crosslinking solutions was analyzed further. Lowest absorbance in each treatment had been targeted by optimization using response surface methodology (RSM). The three-level factorial design had been performed with F-value, and
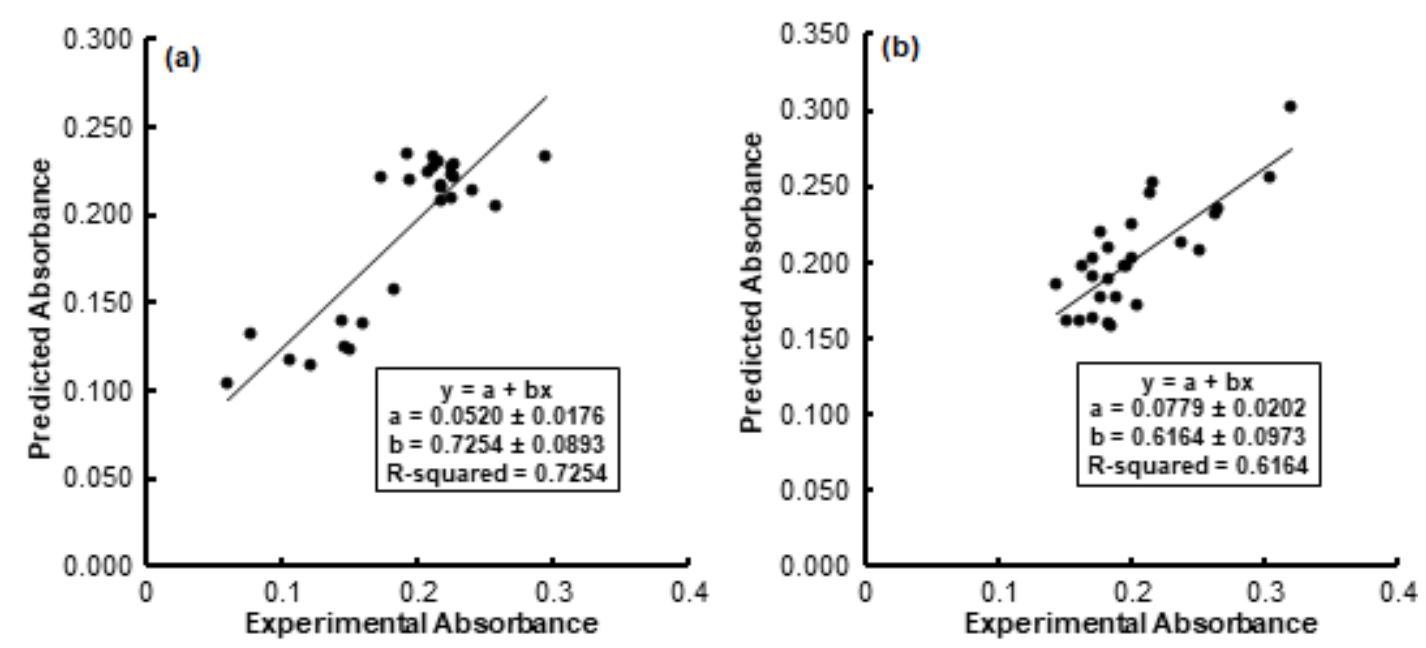

Fig 5. Linear fitting plot of absorbance data and absorbance response from the model, (a) clove oil crosslinking solution and (b) formaldehyde crosslinking solution
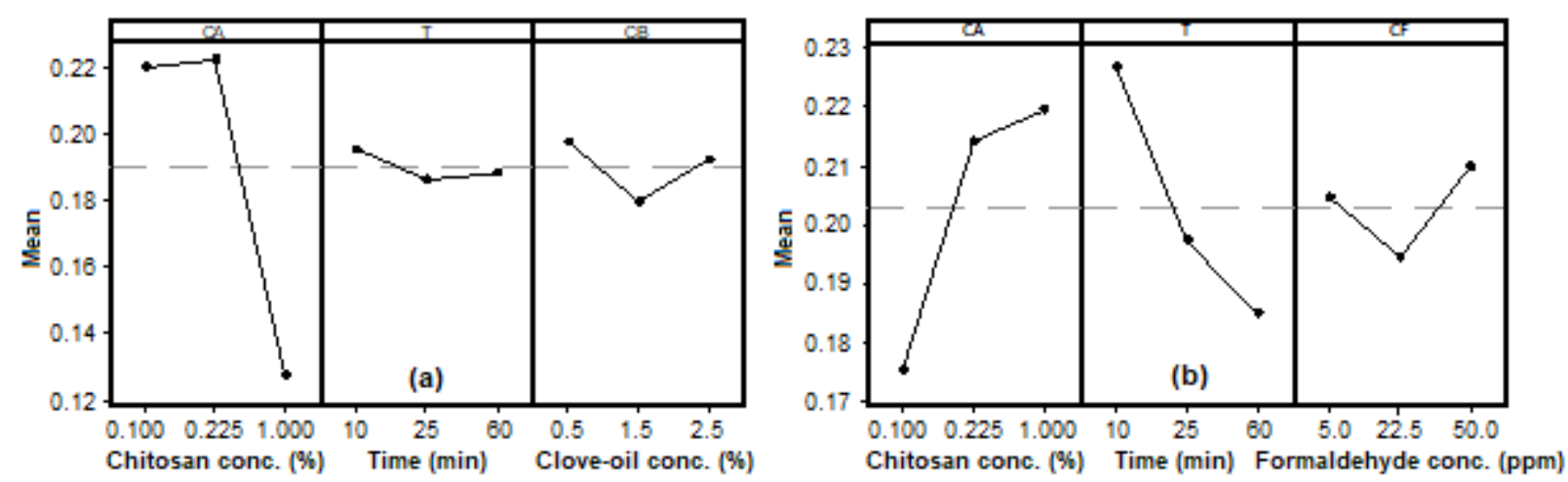

Fig 6. Each parameter effect on the responses, (a) clove oil and (b) formaldehyde addition 
Table 4. Analysis of variance on fastness test of the crosslinking solution

\begin{tabular}{lcccc}
\hline \multirow{2}{*}{ Source } & \multicolumn{2}{c}{$\begin{array}{c}\text { Clove oil crosslinking } \\
\text { solution }\end{array}$} & \multicolumn{2}{c}{$\begin{array}{c}\text { Formaldehyde crosslinking } \\
\text { solution }\end{array}$} \\
\cline { 2 - 5 } Model & F-value & P-value & F-value & P-value \\
Linear & 4.99 & 0.002 & 3.07 & 0.022 \\
CA & 0.51 & 0.681 & 5.76 & 0.007 \\
CB & 0.33 & 0.575 & 5.96 & 0.026 \\
T & 1.05 & 0.32 & 0.43 & 0.52 \\
Square & 0.16 & 0.696 & 10.29 & 0.005 \\
CA $\times$ CA & 0.77 & 0.528 & 2.33 & 0.111 \\
CB $\times$ CB & 0.96 & 0.342 & 4.77 & 0.043 \\
T $\times$ T & 1.12 & 0.305 & 0.80 & 0.383 \\
$2-W a y$ Interaction & 0.22 & 0.642 & 1.42 & 0.25 \\
CA $\times$ CB & 0.39 & 0.762 & 3.46 & 0.04 \\
CA $\times$ T & 0.16 & 0.695 & 3.28 & 0.088 \\
CB $\times$ T & 0.95 & 0.344 & 6.43 & 0.021 \\
\hline R-squared & 0.06 & 0.809 & 0.66 & 0.427 \\
\hline
\end{tabular}

$\mathrm{P}$-value as seen in Table 4. Analysis of variance (ANOVA) for clove oil crosslinking solution gives better result compared to formaldehyde crosslinking solution if $\mathrm{P}$ value is used to evaluate the model. However, the proposed adequacy models for Equation (3) and (4) are represented by P-value 0.002 and 0.022 respectively which shows statistical significance due to the small number of $\mathrm{P}$-value of lower than 0.05 . This indicates that the model proposed in Equation (3) and (4) is appropriate to reflect the effect of each parameter to the degree of fastness.

The low R-squared values (Fig. 5 and Table 4), < $75 \%$, indicates that the dependent parameters of the model did not show the trend of the independent parameters. However, a high R-squared-valued model does not always mean a good model. To evaluate this Rsquared value, residual plots were conducted to further explain the model. The residual plot in Fig. 7 indicates that the models showed good predictive value as the residual plots for both the clove oil and formaldehyde models were scattered without a discernible trend. The initial hypothesis that the dependent variables would affect the independent variable can thus be accepted.

The left side of the graph in Fig. 8 presents the minimum absorbance of $<0.12$ at $1.0 \%$ chitosan concentration and $0.75-2.5 \%$ clove oil concentration for the first graph, and for 40-60 min immersion in 1.0\% chitosan for the second graph. The last figure on the left indicates a minimum absorbance of $0.18-0.20$ at $0.75-2.4 \%$
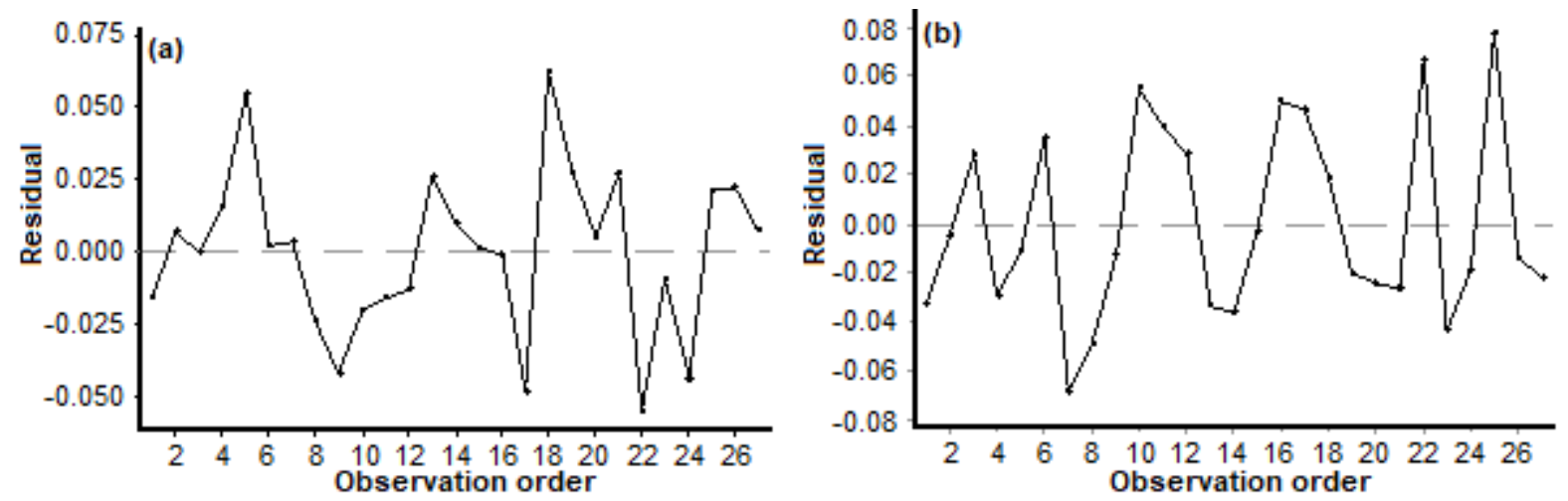

Fig 7. Residual plot of the model (a) clove oil crosslinking solution and (b) formaldehyde crosslinking solution 


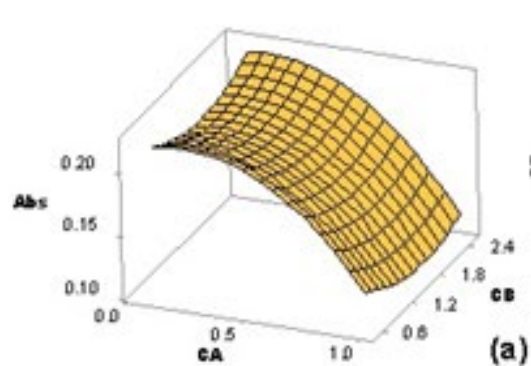

(a)
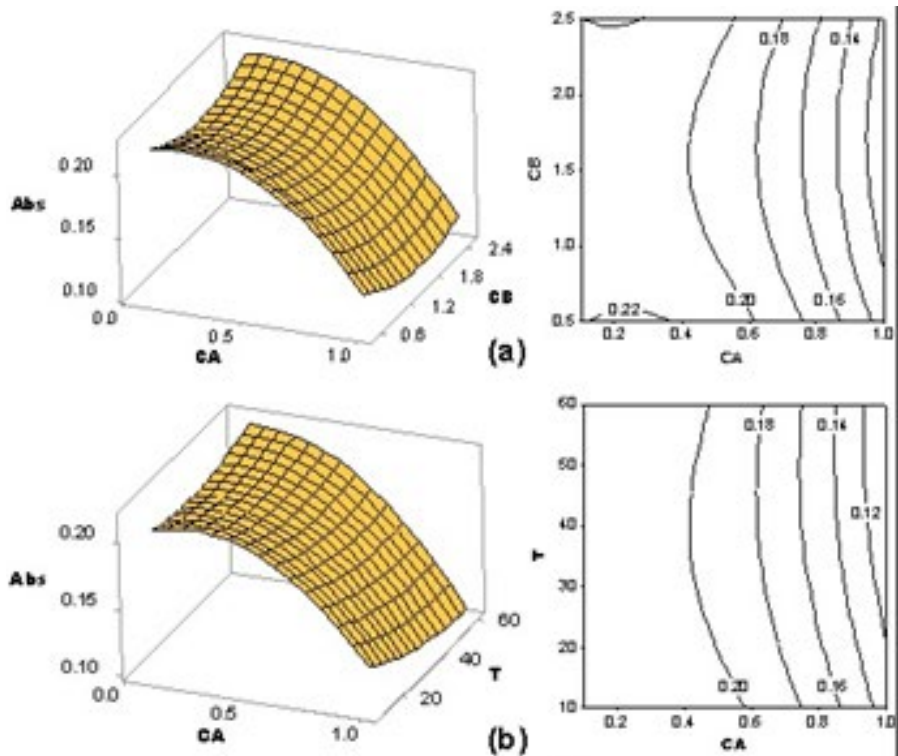

(b)

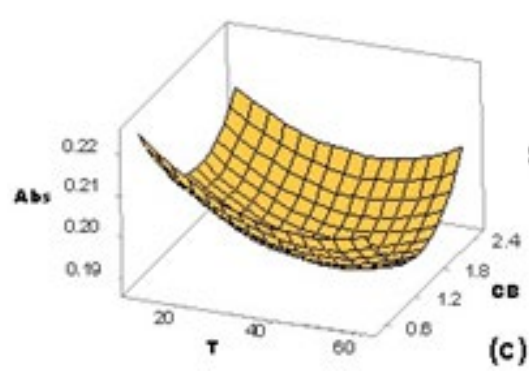

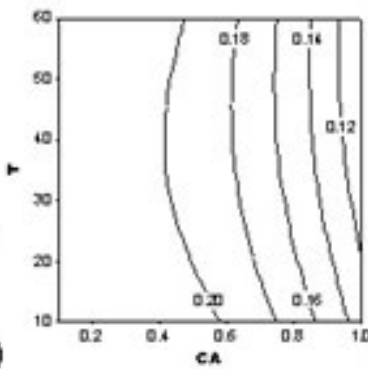

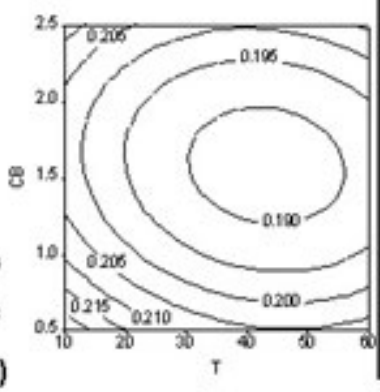

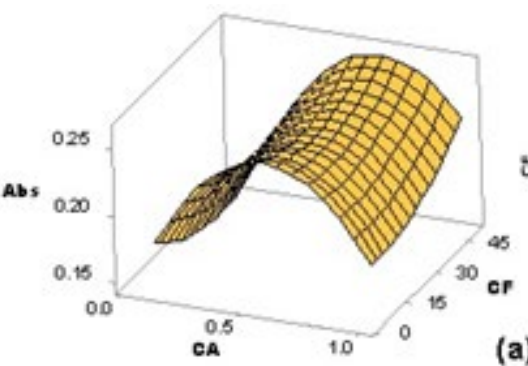

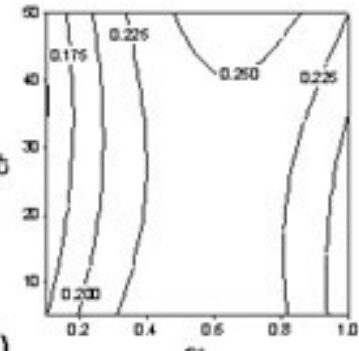

(a)
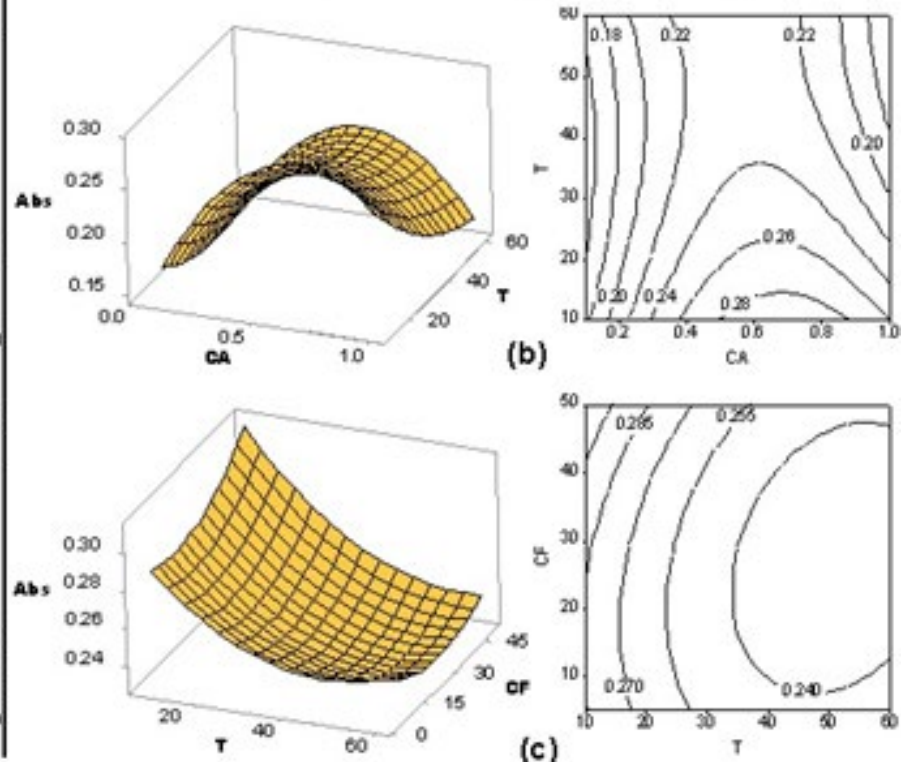

(b)

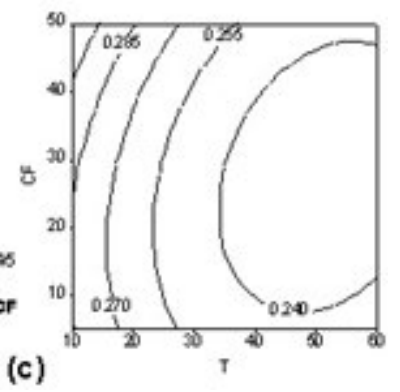

Fig 8. Contour and surface plot of parameters against the response; left image for clove oil and the right image for chitosan (a) CA vs CF, (b) CA vs T, and (c) T vs CB

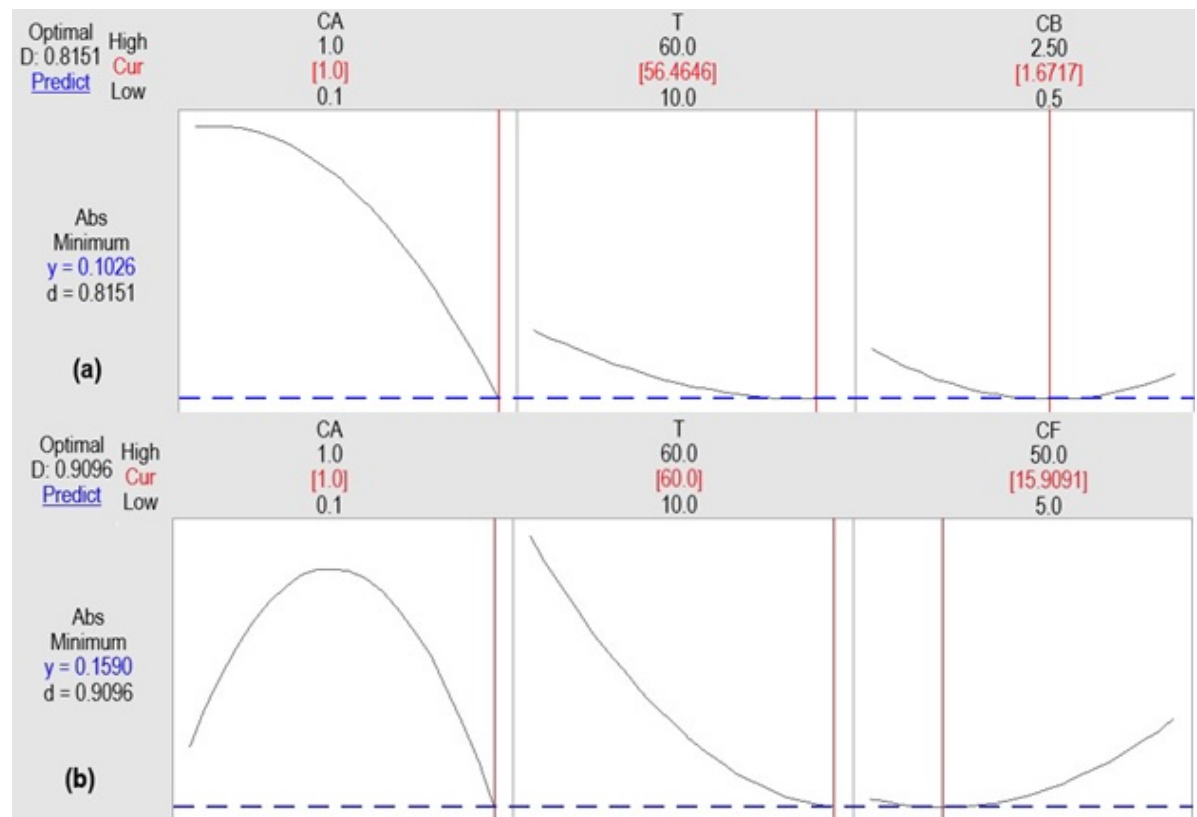

Fig 9. The optimum condition for (a) clove oil crosslinking solution and (b) formaldehyde crosslinking solution 
clove oil concentration and 20-60 min immersion. The right side of the graph presents a minimum absorbance of $<0.16$ at $0.1 \%$ chitosan concentration and $10-50 \mathrm{ppm}$ formaldehyde concentration for the first graph, and 2060 min immersion in $1.0 \%$ chitosan concentration. The third graph on the right side reflects minimum absorbance at a value of 0.24 at 5-45 ppm formaldehyde concentration and 40-60 min of immersion time.

Optimization for all parameters was also conducted to determine the best conditions for the two crosslinker solutions. The result of optimization, as can be seen in Fig. 9 , resulted in the lowest absorbance at 0.103 and 0.159 for clove oil and formaldehyde crosslinking solutions, respectively. The optimum condition for the clove oil crosslinking solution occurred at $1 \%$ chitosan concentration, $1.672 \%$ clove oil concentration, and $56.5 \mathrm{~min}$ immersion time. Meanwhile, the optimum parameters for the formaldehyde crosslinking solution took place at $1 \%$ chitosan concentration, $15.91 \mathrm{ppm}$ formaldehyde, and $60 \mathrm{~min}$ immersion time. The ideal concentration of chitosan for both crosslinking methods was $1 \%$. It reflected that at $1 \%$ chitosan concentration, the fabric was totally covered in the bonding of cellulosechitosan-antifungal agent. Moreover, the optimum concentration of clove oil was not significantly different from that in Muresan et al. [22] and Chinta et al. [24]. The optimum formaldehyde concentration in this study is observed below the limit for infant's fabric, $20 \mathrm{ppm}$ [25].

\section{Determination of Antifungal Properties}

To test the antifungal properties of clove oil and formaldehyde, antifungal testings were carried out against Aspergillus niger for $72 \mathrm{~h}$. The results for control, clove oiltreated, and formaldehyde-treated samples are shown in Fig. 10(a), (b), and (c) respectively. Colony growth measurement and the percent area of fungal growth were also analyzed in this study. Table 5 shows the area of fungal growth and the significance levels obtained using ANOVA test and LSD calculation. Significance level test was used to describe the differences in colony growth and the percentage area of fungal growth in every treatment to confirm the antifungal properties of the modified fabric.

The results shown in Table 5 indicate that formaldehyde was very effective in inhibiting fungal growth. Clove oil, on the other hand, presented insignificant results compared to the control sample. Thus, clove oil was not a suitable antifungal compound to combat Aspergillus niger growth in this study. Furthermore, formaldehyde showed statistically significant results and gave the lowest scale of bacteria growth compared to control and clove oil treatment. It is well known that formaldehyde is a remarkable substance for disinfection and sterilization of inactive microorganisms. It has been reported that formaldehyde could alkylate amino and sulfhydryl groups contained on protein and purine bases [30]. It is worthwhile to note that chitosan is also an antifungal compound with biostatic properties against fungi, which might enhance the antifungal effect.
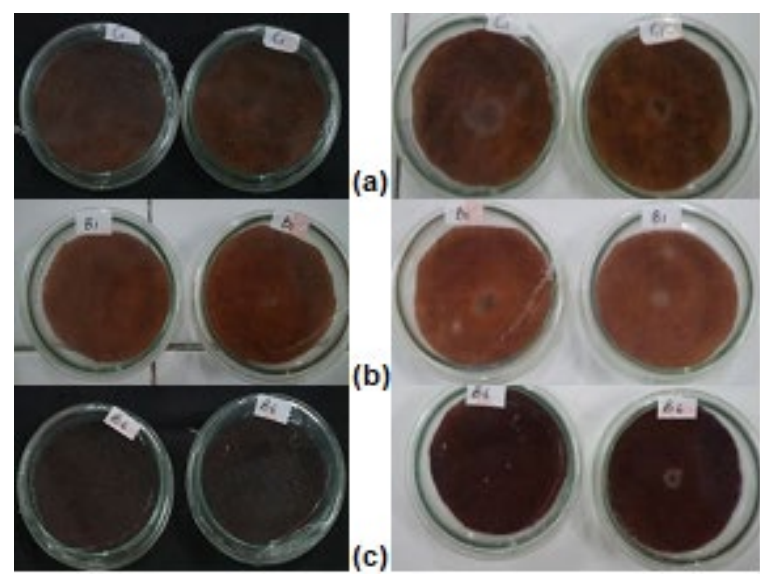

Fig 10. Fungal growth on potato dextrose broth medium (a) control, (b) clove oil crosslinking treatment, and (c) formaldehyde crosslinking treatment for $48 \mathrm{~h}$ and $72 \mathrm{~h}$

Table 5. Antifungal test results on crosslinking of clove and formaldehyde oils after $72 \mathrm{~h}$

\begin{tabular}{|c|c|c|c|c|c|c|}
\hline \multirow{2}{*}{ Treatment } & \multirow{2}{*}{$\begin{array}{l}\text { Initial fabric } \\
\text { diameter, } \mathrm{cm}\end{array}$} & \multicolumn{2}{|c|}{ Diameter, $\mathrm{cm}$} & \multirow{2}{*}{ Average, $\mathrm{cm}$} & \multirow{2}{*}{ Growth, \% } & \multirow{2}{*}{ Scale } \\
\hline & & Test 1 & Test 2 & & & \\
\hline $\mathrm{C} 1$ & 6.00 & 4.32 & 3.54 & $3.93 \pm 0.55^{c}$ & $42.90 \pm 12.89^{c}$ & 3 \\
\hline Clove oil & 6.00 & 3.20 & 3.32 & $3.26 \pm 0.08^{c}$ & $29.52 \pm 1.56^{\mathrm{c}}$ & 2 \\
\hline Formaldehyde & 6.00 & 1.08 & 0.78 & $0.93 \pm 0.21^{\mathrm{a}}$ & $2.40 \pm 1.22^{\mathrm{a}}$ & 1 \\
\hline
\end{tabular}


Table 6. The optimum condition of crosslinking solution consideration

\begin{tabular}{lcccccc}
\hline Treatment & $\begin{array}{c}\text { Chitosan } \\
\text { concentration, } \%\end{array}$ & $\begin{array}{c}\text { Time, } \\
\min \end{array}$ & $\begin{array}{c}\text { Antifungal } \\
\text { concentration, ppm }\end{array}$ & Absorbance & $\begin{array}{c}\text { Fungus growth } \\
\text { area, } \%\end{array}$ & Restriction \\
\hline Clove oil & 1 & 56.5 & 16717.20 & 0.103 & $29.53^{\mathrm{c}}$ & Cost $^{2}$ \\
Formaldehyde & 1 & 60.0 & 15.91 & 0.160 & $2.47^{\mathrm{a}}$ & $\begin{array}{c}\text { Safety and } \\
\text { Environment }\end{array}$ \\
\hline
\end{tabular}

Based on Fig. 9, Table 5, and Fig. 10, the optimal conditions for the preparation of clove oil-based and formaldehyde-based antifungal fabrics are summarized in Table 6. The excessive amount of clove oil was ten thousand times larger than formaldehyde. Restriction parameter was also made to give a brief comparison of the crosslinking solution.

The application of clove oil would boost the price of batik while formaldehyde would pose environmental concerns given its toxicity. The maximum safe exposure to formaldehyde is $0.75 \mathrm{ppm}$ by inhalation, measured as an $8 \mathrm{~h}$ time-weighted average (TWA), and $2 \mathrm{ppm}$ for a short-term exposure limit (STEL) of $15 \mathrm{~min}$ [31-32]. Despite the fact that the formaldehyde is stabilized with a crosslinking agent, textiles employees need to be limited from direct exposure using standard safety equipments. Closed-process systems could be constructed to minimize exposure to formaldehyde, but this would be costly. With all safety and environmental considerations, the optimal conditions in this study were achieved with the application of the formaldehyde crosslinking solution. The use of formaldehyde and clove oil in the crosslinking solutions in this study were reliable for cotton fabric application because the reaction mechanisms do not involve natural dyes. We believe that research into other optimal processes could potentially lead to other antifungal crosslinking methods.

\section{- CONCLUSION}

This study aimed at finding the most suitable conditions for the preparation of antifungal Batik fabrics colored with Gambier-based natural dye. Either clove oil or formaldehyde was used as antifungal compounds, and chitosan was used as a crosslinker that facilitates the immobilization through bonding between the antifungal compounds and the cellulose fiber of the fabric. The results showed that formaldehyde is better than clove oil to use in conjunction with Gambier extracts as natural dyes. The optimal conditions for the preparation of a stable antifungal batik fabric were at $1 \%$ chitosan concentration, $15.91 \mathrm{ppm}$ formaldehyde, and $60 \mathrm{~min}$ immersion time, with absorbance intensity of released antifungal substances after fastness test of 0.159 and fungal growth areas of $2.47 \%$. Although the application of formaldehyde as an antifungal agent still requires environmental and safety considerations regarding its toxicity, it showed better antifungal properties compared to clove oil in this study and could significantly suppress Aspergillus niger growth with a statistically significant result. In general, this study contributes to forwarding optimal conditions for the incorporation and immobilization of antifungal compounds to natural dye-colored fabrics, using crosslinker in the immobilization strategy.

\section{- ACKNOWLEDGMENTS}

The Department of Chemical Engineering, Universitas Gadjah Mada is gratefully acknowledged for the support and facility.

\section{- REFERENCES}

[1] The Jakarta Post, 2009, Batik selected for UNESCO cultural heritage list, https://www.thejakartapost.com/ news/2009/09/08/batik-selected-unesco-culturalheritage-list.html, accessed on 4 May 2019.

[2] Widiawati, D., 2018, The utilization of batik pattern and natural dyes as valuation of the local value in batik society, Jurnal Sosioteknologi, 17 (2), 208-219.

[3] Shahid, M., Islam, S., and Mohammad, F., 2013, Recent advancements in natural dye applications: A review, J. Cleaner Prod., 53, 310-331.

[4] Islam, S., Shahid, M., and Mohammad, F., 2013, Perspectives for natural product based agents 
derived from industrial plants in textile applicationsa review, J. Cleaner Prod., 57, 2-18.

[5] Kasiri, M.B., and Safapour, S., 2013, "Natural dyes and antimicrobials for textiles" in Green materials for energy, products and depollution. Environmental chemistry for a sustainable world, Eds. Lichtfouse, E., Schwarzbauer, J., and Robert D., vol. 3, Springer, Dordrecht, 229-286.

[6] Haji, A., Mehrizi, M.K., and Sharifzadeh, J., 2016, Dyeing of wool with aqueous extract of cotton pods improved by plasma treatment and chitosan: Optimization using response surface methodology, Fibers Polym., 17 (9), 1480-1488.

[7] Kiumarsi, A., Gashti, M.P., Salehi, P., and Dayeni, M., 2017, Extraction of dyes from Delphinium Zalil flowers and dyeing silk yarns, J. Text. Inst., 108 (1), 66-70.

[8] Gashti, M.P., Katozian, B., Shaver, M., and Kiumarsi, A., 2014, Clay nanoadsorbent as an environmentally friendly substitute for mordants in the natural dyeing of carpet piles, Color. Technol., 130 (1), 54-61.

[9] Dhalimi, A., 2015, Permasalahan Gambir (Uncaria gambir L.) di Sumatera Barat dan alternatif pemecahannya, Perspektif, 5 (1), 46-59.

[10] Gove, P.B., 1966, Webster's third new international dictionary of the English language, unabridged, G. \& C. Merriam, Springfield, Mass.

[11] Gao, Y., and Cranston, R., 2008, Recent advances in antimicrobial treatments of textiles, Text. Res. J., 78 (1), 60-72.

[12] Paul, R., 2014, Functional finishes for textiles: Improving comfort, performance and protection, $1^{\text {st }}$ Ed., Woodhead Publishing.

[13] Rahman, M.A., Ahsan, T., and Islam, S., 2010, Antibacterial and antifungal properties of the methanol extract from the stem of Argyreia argentea, Bangladesh J. Pharmacol., 5 (1), 41-44.

[14] Rubbo, S.D., Gardner, J.F., and Webb, R.L., 1967, Biocidal activities of glutaraldehyde and related compounds, J. Appl. Bacteriol., 30 (1), 78-87.

[15] Sarkar, R.K., De, P., and Chauhan, P.D., 2003, Bacteria-resist finish on cotton fabrics using natural herbal extracts, Indian J. Fibre Text. Res., 28 (3), 322-331.

[16] Walentowska, J., and Foksowicz-Flaczyk, J., 2013, Thyme essential oil for antimicrobial protection of natural textiles, Int. Biodeterior. Biodegrad., 84, 407-411.

[17] Pinto, E., Vale-Silva, L., Cavaleiro, C., and Salgueiro, L., 2009, Antifungal activity of the clove essential oil from Syzygium aromaticum on Candida, Aspergillus and dermatophyte species, J. Med. Microbiol., 58 (11), 1454-1462.

[18] Emmons, C.W., 1933, Fungicidal action of some common disinfectants on two dermatophytes, Arch. Derm. Syphilol., 28 (1), 15-21.

[19] Klein, M., and Deforest, A., 1983, "Principles of viral inactivation" in Disinfection, Sterilization, and Preservation, Eds., Block, S.S., $3^{\text {rd }}$ Ed., Lea \& Febiger, Philadelphia, 422-434.

[20] McCulloch, E.C., and Costigan, S., 1936, A comparison of the efficiency of phenol, liquor cresolis, formaldehyde, sodium hypochlorite and sodium hydroxide against Eberthella typhi at various temperatures, J. Infect. Dis., 59 (3), 281-284.

[21] Sagripanti, J.L., Eklund, C.A., Trost, P.A., Jinneman, K.C., Abeyta Jr., C., Kaysner, C.A., and Hill, W.E., 1997, Comparative sensitivity of 13 species of pathogenic bacteria to seven chemical germicides, Am. J. Infect. Control, 25 (4), 335-339.

[22] Muresan, A., Cerempei, A., Dunca, S., Muresan, R., and Butnaru, R., 2009, Aromatherapeutic characteristics of cotton fabrics treated with rosemary essential oil, Cellul. Chem. Technol., 43 (910), 435-442.

[23] Kang, H.C., Park, Y.H., and Go, S.J., 2003, Growth inhibition of a phytopathogenic fungus, Colletotrichum species by acetic acid, Microbiol. Res., 158 (4), 321-326.

[24] Chinta, S.K., Landage, S.M., Abhishek, A., Sonawane, K.D., and Jalkate, C., 2012, Medical textiles-application of essential oil as antimicrobial agent on nonwoven, $G J B B, 1$ (1), 75-80.

[25] United States Government Accountability Office, 
2010, Formaldehyde in textiles: While levels in clothing generally appear to be low, allergic contact dermatitis is a health issue for some people, http://www.gao.gov/products/GAO-10-875, accessed on 28 November 2018.

[26] Bezerra, M.A., Santelli, R.E., Oliveira, E.P., Villar, L.S., and Escaleira, L.A., 2008, Response surface methodology (RSM) as a tool for optimization in analytical chemistry, Talanta, 76 (5), 965-977.

[27] Montgomery, D.C., 2017, Design and analysis of experiments, $9^{\text {th }}$ Ed., John Wiley \& Sons, Inc., Hoboken, New Jersey, USA.

[28] Rahayuningsih, E., Pamungkas, M.S., Olvianas, M., and Putera, A.D.P., 2018, Chlorophyll extraction from suji leaf (Pleomele angustifolia Roxb.) with ZnCl2 stabilizer, J. Food Sci. Technol., 55 (3), 10281036.

[29] Vedaraman, N., Sandhya, K.V., Charukesh, N.R.B.,
Venkatakrishnan, B., Haribabu, K., Sridharan, M.R., and Nagarajan, R., 2017, Ultrasonic extraction of natural dye from Rubia Cordifolia, optimisation using response surface methodology (RSM) \& comparison with artificial neural network (ANN) model and its dyeing properties on different substrates, Chem. Eng. Process., 114, 46-54.

[30] Favero, M., 1991, "Chemical disinfection of medical and surgical materials" in Disinfection, Sterilization, and Preservation, Eds. Block, S.S., $4^{\text {th }}$ Ed., Lea \& Febiger, Philadelphia, 617-641.

[31] Occupational Safety and Health Administration, 1991, OSHA amends formaldehyde standard, United States Department of Labor.

[32] Occupational Safety and Health Administration, 2007, Toxic and hazardous substances. Formaldehyde, United States Department of Labor, Code of Federal Regulations: 29 CFR 1910.1048. 